\title{
Критическая теория: этапы идейного развития
}

XXI в. встретил нас цивилизационным кризисом, диагностируемым в разных сфрерах человеческого общества. Прогнозам политологов о возникновении нового глобального мирового пространства без антагонизмов и войн, существование которого якобы стало возможно после падения Берлинской стены, положили конец военные операций НАТО на Балканском полуострове, в Афганистане и Ираке после событий 11 сентября 2001 г. Энтузиазм, связанный с ростом экономики, сменился экономической посткризисной депрессией, инициированной негативными экономическими событиями 2008 г. Наступление неолиберализма на социальные права и крах концепции "государства всеобщего благосостояния" спровоцировали депрессию у целого поколения, привыкшего к государству-няньке. Массовая культура, вопреки ожиданиям, окончательно превратилась из инструмента духовного обогащения в коммерческую машину, сконструированную в соответствии с логикой товарного производства. Очевидно, что текущий кризис ведет нас за пределы тех узких областей, в которых он локализуется, и требует более глубокого анализа.

Существует ли методология, позволяющая определить более глубокие основания кризисов, чем те, которые могут быть описаны частными гуманитарными науками? В интеллектуальной истории XX в. таким универсалистским дискурсом, претендующим на право диагностировать общий кризис человеческой культуры, оказалась критическая теория, возникшая на стыке марксизма, психоанализа, структурализма и рефлексии антиколониальной борьбы в странах третьего мира. Целью данной небольшой работы является обзор идейных предпосылок и базовых положений критической теории в аспекте реконструкции этапов её идейного развития.

Критическая теория представляет собой совокупность подходов и теорий, объединенных общими принципами, в числе которых - политическая ангажированность, критическое отношение к устоявшимся социальным практикам, междисциплинарность и отрицание позитивистской теории научной методологии [12]. В силу ее теоретического многообразия сложно определить общие методы каждого направления, однако можно проследить общие тенденции в процессе формирования критической теории в разных странах. Первый этап критической теории традиционно связывается с деятельностью нескольких немецких социологов и философов, работавших совместно в Университете им. Гёте во Франкфурте-на-Майне в рамках Института социальных исследований, созданном Максом Хоркхаймером. В этот период, границы которого определены созданием института в 1924 г. и началом эмиграции большинства его сотрудников с приходом нащистов к власти в 1933 г., основными представителями критической теории становятся в первую очередь Теодор Адорно и собственно Макс Хоркхаймер, которому принадлежит авторство названия нового теоретического направления в немецкой социологии и философии. Исходными задачами критической теории явились анализ и попытка преодоления тех проблем, с которыми столкнулась классическая марксистская методология в новых исторических условиях изменившегося капитализма XX в.

Кроме указанных авторов, значительное влияние на формирование критической теории в этот период оказали эстетические идеи Вальтера Беньямина и работа Герберта Маркузе в области изучения немецкой классической фрилософиии и френоменологии. Основной проблемой, определившей дальнейший ход развития всей критической теории, становится изучение влияния культуры на воспроизводство социальной иерархии. В отличие от многих

(C) Тютченко Д. А., 2021

ТЮТЧЕНКО Даниил Аркадьевич, студент Дальневосточного федерального университета (2. Владивосток). E-mail: tyutchenko.da@students.dvfu.ru 
представителей немецкой левой среды, к которой в разной мере относили себя названные выше авторы, все они достаточно скептически отнеслись к интенсивному формированию массовой культуры, форсированной появлением средств технической репродукции предметов искусства и бурным развитием индустрии кино и фотографоии.

Ярким примером этой установки может служить первый текст, положивший начало этой тенденции, "Произведение искусства в эпоху его технической воспроизводимости", написанный Вальтером Беньямином в 1936 г., представляющий из себя своеобразную рефлексию двух кризисов: эстетического, вызванного появлением новых средств репродукции произведений искусства, выстраивающих особую связь между объектом и публикой, и политического, развернувшегося на фоне победы фрашистских партий в Европе и становления тоталитаризма в Германии [4]. По мнению Беньямина, процесс, лежащий в основе формирования массовой культуры, основанный на репродукции классических предметов искусства, ведет к потере его ауры. Текст иллюстрирует основную проблематику критической теории в период ее фрормирования: связь между общепринятой культурой и идеологической гегемонией правящего класса, эстетической и политической практикой, классовым сознанием и его ролью в социальной борьбе. Также этот текст отражает важный принцип критической теории, присущий всему многообразию ее фрорм, который можно определить как политико-практическую ангажированность. Беньямин не скрывает, что видит выход из двойственного кризиса, эстетического и политического, в борьбе пролетариата, так как это единственный класс, способный противостоять капитализму, в рамках рыночной логики которого превращение предметов искусства в товар становится закономерностью.

Исследования других представителей Франкфуртской школы соответствуют той же тенденции и принципам, но Адорно и Хоркхаймер продвинулись далее в своих рассуждениях и попытались связать наблюдаемое ими формирование массовой культуры с общими установками, лежащими в европейской традиции Просвещения. Результатом этого критического подхода ко всему проекту Модерна стала их совместная книга "Диалектика Просвещения" (1947), задача которой заключалась в анализе роли модернистского способа мышления в формировании отношений господства/подчинения и укрепления иерархии на уровне эпистемологических установок. Именно в этой работе Адорно и Хоркхаймер впервые обращаются к наследию Ницше, рассматривая его этические взгляды как закономерное развитие принципа Просвещения, провозгласившего разум единственный инстанцией нравственности. Несмотря на то, что в этом основополагающем для критической теории тексте фрилософия Нищше выступает в качестве завершенной критики практического разума, начатой Просвещением [1], нельзя не заметить, что философия Ницше оказала огромное влияние на фрормирование критического дискурса во Франции, без описания которого любой разговор о критической теории был бы неполным.

Именно французский период становления критической теории можно назвать следующим, вторым, этапом ее формирования. Как было отмечено выше, методологическим основанием критической теории в период её возникновения в Германии стали идеи Маркса и Фрейда. Это также верно для Франции, где рецепция марксизма и психоанализа послужили фрундаментом генезиса новых подходов в гуманитарных науках. Однако фрранцузская мысль этого периода испытала не меньшее влияние структуралистского метода, предложенного швейцарским франкоязычным лингвистом Фердинандом де Соссюром, теория которого стала активно применяться в исследованиях культуры и интеллектуальной истории. Развитие критической теории во Франции связано в первую очередь с именами Ролана Барта и Мишеля Фуко, которые первыми стали использовать структуралистский метод в анализе современного им общества. Французская критическая теория развивалась параллельно немецкой и практически никак не соприкасалась с ней, но отнести их к одному направлению позволяют общие принципы исследования, методологические основания в виде марксизма и психоанализа и общая проблематика. Критическая теория во Франщии, как и в Германии, обращает своё внимание в первую очередь на вопрос роли культуры и знания в воспроизводстве властных отношений. Лучшей иллюстрацией этого специфического 
синтеза Маркса, Фрейда и Соссюра, используемых для критики идеологии в обобщенном марксистском смысле этого слова, может служить классическая работа Ролана Барта "Мифологии", в которой автор рассматривает мифр как вторичную семиологическую структуру, встроенную в систему идеологического воспроизводства буржуазного общества, используя в качестве дескриптивной конструкции структуру бессознательного, предложенную Фрейдом [3, c. 35]. Это сближает критику мифа Барта с теорией Адорно и Хоркхаймера, рассматривающих современный миф как продукт внутренней диалектики Просвещения, воплощенной в эпосе об Одиссее.

Работы Мишеля Фуко менее сконцентрированы на понятии идеологии, однако он стоял у истоков критического осмысления отношения между властью и производством научного знания. В своей книге "Надзирать и наказывать" (1975) он предлагает отказаться от бинарной оппозиции насилие/ идеология [10, с. 34], обращаясь к третьему элементу, который критическая теория до Фуко зачастую обходила стороной. Этим третьим звеном в воспроизводстве власти в теории Фуко становится специфическое научное знание о человеке, границы которого определены текущей диспозицией внутри пространства иерархии или "совокупностью стратегических позиций господствующего класса" [10, с. 36], как отмечает автор. Представляется, что заслуга Фуко, если рассматривать его интеллектуальное наследие в рамках критической теории, заключается прежде всего в деконструкции господствующего прежде взгляда на истину как нечто независимое от режима функционирования власти. Несмотря на оригинальный подход, проблематика, рассматривая Фуко, совпадает с общей тенденцией внутри критической теории, направленность которой определялась потребностями анализа отношений власти и их воспроизводства с помощью практик, принадлежащих к области культуры. Аналогичное утверждение верно и в отношении Барта, исследования которого представляют из себя в первую очередь фрилософию языка и развитие семиотики, однако его теория с самого начала обладала ангажированным и критическим характером, благодаря которому исследования языка обретали связь с социальной критикой. В случае Фуко мы также сталкиваемся с важным сходством с немецкой критической теорией: его критика направлена не только против буржуазного общества, но рассматривает развитие культуры в целом. Несмотря на то, что по мнению Фуко, капитализм создал особую конфигурацию отношений между властью и знанием, лучше всех других поддающуюся анализу, он также обращает внимание на развитие этого отношения в добуржуазных обществах, например, акцентируя внимание на развитии концепта безумия, берущего свое начало в классической эпохе. По аналогии с Бартом, этот фракт сближает Фуко с другими критическими теоретиками, предметом рассмотрения которых становится не только капиталистическое общество, но и предшествующие ему формы отношения между культурой и отчуждением.

Другой схожей чертой двух разных вариантов критической теории можно назвать антропологизм. Огромное влияние на представителей её немецкой школы оказала публикация рукописей Маркса 1844 г., неопубликованных при его жизни. Нарратив этих черновиков сильно выделяется на фоне основной тематики наиболее известных сочинений Маркса. Их радикальный антропоцентризм совпадает с рядом других работ, написанных в короткий период между 1843 и 1845 гг., который можно выразить следующей сентенцией из "К критике гегелевской философии права": "Быть радикальным - значит понять вещь в её корне. Но корнем является для человека сам человек" [6, с. 422]. Однако именно в этих рукописях Маркс впервые пытается предложить историософскую концепцию, согласно которой исторический процесс представляет из себя отчуждение человека от его собственной сущности. Несложно заметить, что такая постановка вопроса наследует философской антропологии Фейербаха, но между ними есть важное различие. Маркс интегрирует в концепцию Фейербаха понятие отчужденного труда, таким образом связывая её с политэкономией и социальной структурой. С точки зрения Маркса, именно эта смена перспективы позволяет подвергнуть критике представление Фейербаха об абстрактном человеке, поместив его в социальный контекст и рассмотреть сущность индивидов как продукт конкретных общественных отношений. Эта позиция нашла свое отражение в знаменитых "Тезисах о Фейербахе". Затем взгляды Маркса на антропоцентризм радикально меняются и в более поздних 
сочинениях он уже не обращается к понятию отчуждения в его философрском значении, перенося его в область политической экономии и товарного обмена. Однако именно эта гуманистическая теория раннего Маркса послужила своеобразным фундаментом развития немецкой критической теории, возвращающейся к концепции отчуждения в контексте критики культурных паттернов Просвещения. По мнению Адорно и Хоркхаймера, в этих модернистских установках изначально был заложен принцип овеществления, рассматривающий природу и человека как средство, подчиняя его функционированию созданных им же общественных отношений. Таким образом, критическая теория в ее ранней версии реактулизирует теорию отчуждения, делая центром своей проблематики границы человеческой самореализации в капиталистическом обществе и её отношение с властью, выходящую за пределы узкой области политических актов.

Схожую интенцию можно обнаружить в текстах Мишеля Фуко, несмотря на то, что он никогда не вдохновлялся марксистским гуманизмом. Более того, он был крайне критично настроен к любым антропоцентристским интерпретациям Маркса и не пытался вернуть социальную теорию к концепту отчуждения. Решающее влияние на формирование его взглядов оказали теории Луи Альтюссера и Клода-Леви Стросса, критиковавших не только популярное во Франции экзистенциалистское прочтение марксизма, но и применение гуманизма в области теории как таковое. И именно Фуко принадлежит известное мнение, что общепринятое представление о человеке, сформированное преимущественно европейским гуманизмом, является достаточно поздним культурным конструктом. Однако переосмысление значения гуманизма и общий тон работ Фуко, соответствующих тенденции критики классического представления о субъекте, не отменяет того, что центральной темой его многочисленных исследований является человек. По словам Фуко, даже его сочинения, посвященные интеллектуальной истории, такие как "Слова и вещи" и "Археология знания", направлены на исследование отдельных механизмов власти в их связи с научным дискурсом [11, с. 234]. Такой пристальный анализ отношений между индивидом и властью, занимающий центральное место в его работах, говорит в пользу того, что основным интересом Фуко является не просто культура и история идей, но их значение для человека и тех социальных отношений, в которые он неизбежно оказывается включенным. Особенно ярко это иллюстрирует поздний период в творчестве Фуко, представленный четырехтомной "Историей сексуальности", ознаменовавшей поворот к новому взгляду на "становление субъектом" и исследованию "культуры себя".

Однако между французским и немецким вариантами критической теории существует ряд расхождений, касающихся в первую очередь роли революционного субъекта. Если представители Франкфуртской школы в ранний, немецкий период своего творчества (особенно Вальтер Беньямин) делают акцент на борьбе рабочего класса, то в работах Мишеля Фуко заметен поворот к новым фрормам социальной борьбы: студенческому движению, защите прав заключенных, мигрантов и других миноритарных групп. Позицию Фуко по этому вопросу может резюмировать его собственная цитата: "Существует интернациональный долг, создающий права и обязанности и состоящий в том, чтобы выступать против любого злоупотребления властью, независимо от того, кто его совершает и кто становится его жертвами. В конце концов, всеми нами управляют, а это значит, что все мы солидарны" [13, с. 338]. В первую очередь такая разница в подходах к анализу борьбы разных социальных групп связана с временным промежутком, который отделяет период возникновения немецкой версии критической теории от французской. Беньямин, Адорно и Хоркхаймером застали период революционного подъема рабочего класса; Фуко, Барт и другие фрранцузские критические теоретики жили в эпоху доминирования редормистских тенденций внутри политики рабочего класса, но наблюдали подъем неизвестных прежде социальных движений. Кроме этого, Фуко в своей теории власти отказывается от перспективы полного уничтожения социального контроля, кажущейся ему утопичной, уделяя внимание в первую очередь борьбе угнетенных против злоупотреблений локальных властных институтов, в работу которых они включены. Такое пессимистичное отношение к потенциалу социальных изменений и представление о субъекте 
этих преобразований существенно отличает фрранцузских критических теоретиков от немецкой.

Следующей важной вехой в развитии критической теории, которую можно назвать третьим этапом ее развития, стал постколониализм и обращение к исследовательской проблематике колонизации в целом. Именно постколониализм может служить примером взаимовлияния внутри критической теории и того, как исследования положения колонизированных народов повлияли на анализ западных обществ, предлагаемый этой традицией.

Разрушение старой колониальной системы во второй половине XX в. стало причиной возникновения новой масштабной академической тенденции, анализирующей влияние колониальной культуры и практик, связанных с ней, на идентичность угнетенных народов и их отношение с бывшими метрополиями и текущей международной системой разделения труда. Спектр этих исследований, получивший название постколониальной теории, оказался не просто рефлексией исторического опыта коренных народов, но изначально занял критическую позицию по отношению к сформировавшимся после деколонизации международным отношениям. Даже такие, как может показаться, локальные исследовательские инициативы, направленные на изучение истории индийского крестьянства в колониальную эпоху, изначально возникали в рамках политически ангажированных журналов [2, с. 163]. Этот политизированный характер постколониальных исследований стал традицией для этого дискурса и не утратил свое значение по прошествии времени. По этой причине постколониальная теория всегда была критически настроена по отношению к новой гегемонии международных структур, стремящихся диктовать свою волю странам, находящимся на периферии капиталистической системы.

В связи с этим анализом положения колонизированных народов важность приобретает понятие "субалтерн", активно используемое постколониальными теоретиками. Этот термин был заимствован из текстов итальянского марксиста Антонио Грамши и стал использоваться по отношению к группам, опыт угнетения которых не получил собственной репрезентации. Именно с помощью этого понятия критическая теория обозначает те группы населения в колониальных странах, угнетение которых имело гетерогенный характер и не может быть описано исключительно в терминах классового, гендерного, расового и любого другого господства, основанного на принадлежности к той или иной единственной идентичности. Опыт борьбы субалтерн-групп и его теоретическая рефлексия в рамках критических исследований важны тем, что обращают внимание на тот факт, что причины кризиса системы могут находиться не только в логике ее собственного развития, но и быть связанными с порожденным ей социальным антагонизмом. В определенный момент понятие "субалтерн" вышло за пределы языка постколониальной теории и стало инструментом анализа отношений господства и подчинения как таковых. Гаятри Спивак в своем эссе "Могут ли угнетенные говорить?" расширяет границы этого понятия и не ограничивает его исключительно критикой европоцентризма, применяя его к анализу политической репрезентации угнетенных в языке интеллектуалов, хотя главным объектом её исследования всё же остается колониальная Индия [8]. Использование этого слова в более ёмком дискурсивном пространстве критической теории ведёт нас к необходимости признания субалтерн-групп за пределами (пост)колониальных обществ. Таким образом, преемственность понятийного аппарата не просто отсылает нас к междисциплинарному характеру критических исследований, но способна проиллюстрировать значение борьбы угнетенных групп по всему миру. Задача такой постановки вопроса в контексте анализа кризиса заключается в осмыслении того, насколько его основания укоренены в борьбе представителей субалтерн-групп за признание. Например, снос памятников генералам-южанам в США или общественные компании по переосмыслению женщинами опыта домогательств, так или иначе являются результатами борьбы с культурой, игнорирующей конкретный опыт угнетения, переживаемый миноритарными социальными группами, однако многие классифицируют эти явления как симптомы глубокого кризиса западного общества. Корреляция между кризисом старой культуры и борьбой угнетенных в свою очередь отсылает нас к другой проблеме: всегда ли кризис является маркером упадка или же это этап, через который необходимо пройти ради возникновения более эгалитар- 
ной и плюральной культуры. Критическая теория с самого начала и по сей день склонна ко второму варианту.

Предлагаемые критической теорией варианты выхода из кризисной ситуации являются логичным продолжением её методологии диагностики кризиса. В частности, следует обратиться к одному из основных методологических принципов данного направления - политической ангажированности, описанной Максом Хоркхаймером в его классическом эссе о критической теории [11]. Заявляя о своем политически ангажированном отношении к капиталистической системе и принадлежности к революционным движениям угнетенных, включая классическое рабочее движение, критическая теория так или иначе апеллировала к разным формам социалистического проекта как способу преодоления кризиса, акцентируя внимание на их демократической и освобождающей составляющей $[\mathbf{9}$, с. 220].

Однако на следующем, четвертом, этапе своего развития критическая теория, не отступая от описанной выше ангажированности, столкнулась с серьезной концептуальной проблемой, связанной с расщеплением того социального субъекта, который долгое время рассматривался единственным носителем творческой силы потенциальных революционных преобразований. Встраивание пролетариата в буржуазную систему потребления и возникновение так называемых государств всеобщего благосостояния заставило представителей критической теории пересмотреть выводы классического социализма о революционной роли рабочего класса. Своё особенно яркое выражение эта тенденция нашла в работах таких известных представителей критической теории, как Жан Бодрийяр и Жан Лиотар. Бодрийяр и Лиотар были активным участниками французской левой политики, и оба стали выразителями тех настроений, с которыми столкнулись фрранцузские левые интеллектуалы после события мая 1968. В своей концепции социальной критики Бодрийяр отказывается от представления, присущего всей прежней критической теории, о субверсивном потенциале борьбы тех или иных социальных групп; расширение границ общества потребления ставит крест на традиционных институтах организации рабочего класса, особенно на партийной борьбе $[5$, c. 36]. $\mathrm{C}$ точки зрения Бодрийяра, культурный кризис его времени, определяемый как утрата связи между означаемым и означающим, делает старые структуры господства и подчинения настолько неустойчивыми, что любое сопротивление им только укрепит их исчезающий авторитет [5, с. 48]. Однако тенденция к деполитизации отразилась далеко не на всей критической теории, и работы Бодрийяра представляет только ее крайний полюс. В целом вышеозначенная проблема, с которой столкнулась критическая теория на фоне спада классовой борьбы в Европе и США, была преодолена с помощью обращения к анализу новых социальных движений, возникших во второй половине прошлого века и приобретших особое значение в условиях переосмысления роли традиционного рабочего класса. По этой причине, например, критика европоцентризма и феминистская теория стали неотъемлемой частью критических исследований. Таким образом, критическая теория не отступила от принципа политической ангажированности и продолжила связывать выход из кризиса с возможностью построения более эгалитарного и инклюзивного общества, обращая внимание не только на привычную экономическую борьбу, но и на маргинальные для капитализма группы, борющиеся за признание.

Репрезентативным примером такого подхода к решению кризиса в рамках критической теории может служить теория Герберта Маркузе. Если в ранний период внимание Маркузе сосредоточено в первую очередь на интерпретации мысли Гегеля и Хайдеггера, старающейся примирить их фрилософию с марксизмом, то после вынужденной эмиграции в Соединенные Штаты одной из центральных тем его работ становится поиск революционного субъекта и осмысление нового революционного опыта, способного преодолеть кризис человеческой культуры. Маркузе анализирует интеграцию пролетариата в буржуазное общество, используя не столько экономические категории, сколько обращаясь к анализу новых форм культурной гегемонии правящего класса, выражающейся в господстве индустрии массовой культуры и институтах "тоталитарной демократии". Эта тенденция внутри критической теории ведет за пределы классического марксистского классового анализа, связывающего револющионную роль той или иной социальной группы с её положением в си- 
стеме разделения труда. В свете этого, Маркузе обращает внимание на борьбу маргинальных групп, не способных принять буржуазный образ жизни и не встроенных в капиталистическую систему потребления. На этом этапе своего развития критическая теория отказывается от свойственного для XIX в. представления, согласно которому интересы угнетенного большинства неизбежно совпадают с уничтожением капиталистической системы. В своем знаменитом эссе "Репрессивная толерантность" Маркузе рассматривает консервативное большинство скорее как препятствие на пути к прогрессу, носителем которого становится гетерогенное меньшинство, различные элементы которого связаны друг с другом лишь своей принципиальной враждебностью статус-кво [7]. Эти положения теории Маркузе, как одного из самых влиятельных критических теоретиков, иллюстрируют смену перспективы, характерной для левой социальной теории второй половины XX в., столкнувшейся с поиском нового социального субъекта, борьба которого способна привести к масштабной эмансипации, с возможностью которой критическая теория связывает выход из кризиса.

Альтернативным решением концептуальной проблемы утраты и поиска нового революционного субъекта может быть современное переосмысление критической теории, предлагаемое бельгийским политическим фрилософром Шанталь Муффр, одним из самых влиятельных левых теоретиков современности. В том числе с возникновением постмарксизма связан современный нам, пятый, этап развития критической теории. Опираясь на таких полярных по взглядам политических теоретиков, как Антонио Грамши и Карл Шмитт, она рассматривает кризис современных европейских обществ как кризис либеральной демократии и политической репрезентации. Она последовательно отстаивает точку зрения, что современный неолиберальный капитализм, и созданная им система постдемократии, превращающая политику в управление, больше не способна обеспечить политическое представительство для широкого спектра угнетенных групп. Её подход к кризису в рамках критической теории выгодно отличается тем, что, во-первых, он акцентирует внимание на определенной тактике сопротивления угнетенных групп и, следовательно, не подвержен апатии, которая на протяжении многих лет сопровождала теоретиков данного направления в XX в.. Во-вторых, она предлагает оригинальную теорию политического антагонизма и репрезентации, включающую в себя переосмысление теоретического наследия Антони Грамши, психоанализа и постструктурализма. Отправным пунктом ее политической теории является критика классического, в том числе марксистского, представления о политическом и классовом антагонизме. Перенося критическую фрилосодрюю языка Мишеля Фуко и Ролана Барта в область непосредственного политического анализа, она приходит к выводу, что любую политическую идентичность, включая идентичность промышленного рабочего класса, необходимо рассматривать как продукт множества несводимых друг к другу дискурсивных практик и языковых игр. Тот же механизм, с точки зрения Муфф,, лежит в основе конструирования любого социального порядка; таким образом, любой социальный порядок является гегемонистским и сконструирован множеством практик, артикулируемых аппаратом власти. Однако любой гегемонистский порядок в силу своей неустойчивости и неокончательности может быть оспорен контргегемонией, носителем которой являются классы и группы, подавляемые в рамках текущей диспозиции сил [14].

В этой возможности контргегемонии Шанталь Муффр видит способ преодоления текущего кризиса, выраженного в первую очередь в кризисе политических систем и утраты доверия масс к либеральной демократии. $\mathrm{C}$ её точки зрения, модусом нового политического мышления левых, способного к артикуляции контргегемонию, является популизм, так как только дискурс способен заново сконструировать политическую идентичность угнетенных, которая не была бы замкнута на партикулярной классовой или любой другой ограниченной повестке. В критических исследованиях гегемонии, проводимых Муфрф, мы сталкиваемся с оригинальным, но вписывающимся в общую традицию критической теории подходом к анализу кризиса и возможности выхода из него.

Резюмируя сказанное выше, можно заключить, что критическая теория - это гетерогенное явление, варианты которого часто развивались параллель- 
но друг другу. Несмотря на неоднородность, в истории ее развития можно выделить ряд этапов, первый из них традиционно можно назвать классическим. Это этап формирования принципов и сферы интересов критической теории, связанный с именами Теодора Адорно, Макса Хоркхаймера, Вальтера Беньямина и деятельностью Института социальных исследований им. Гёте во Франкфурте-на-Майне. Не менее основополагающим для критической теории стал второй период её формирования во Франции, основными фригурами которого были Мишель Фуко и Ролан Барт, опирающиеся не только на наследие Маркса и Фрейда, но и на структуралистскую теорию языка. Затем наступил третий этап, связанный с актуализащией постколониальных исследований и переосмыслением опыта колонизированных народов, в рамках которого оригинальная теория политической репрезентации оказала влияние на все остальные области критической теории. Примерно в это же время критическая теория на Западе столкнулась с важной теоретической проблемой поиска нового революционного субъекта в связи с деполитизацией рабочего класса и развития общества потребления; концептуализацию этой проблемы можно назвать четвертым этапом в её истории. С одной стороны, это породило целую традицию скептического отношения части критических теоретиков, проводниками которой стали Бодрийяр и Лиотар, к потенциалу социальной борьбы. С другой, эта же проблематика стала поводом для обращения к исследованию новых социальных движений, со временем ставших одним из центральных объектов внимания критической теории. Пятый и последний из отмеченных нами этапов - это современная критическая теория, рассмотренная на примере постмарксизма Шанталь Муффф, предпринимающей попытки интегрировать в рамках одного дискурса множество критических подходов с целью осмысления и критики современных западных политических систем. Общим для перечисленных этапов развития и множества упомянутых подходов является в первую очередь принцип политической ангажированности, выдвинутый на первое место основателями критической теории. Именно он стал одним из ведущих фракторов в смене этапов истории теории, сделав ее изначально зависимой от особенной текущей политической реальности и диспозиции сил в борьбе между классами.

\section{Литература}

1. Адорно, Т., Хоркхаймер, М. Диалектика Просвещения / Т. Адорно, М. Хоркхаймер. [Электронный ресурc]. URL: https://gtmarket.ru/library/basis/5521 (дата обращения 15.10.21).

2. Андерсон П. Перипетии гегемонии / П. Андерсон. М.: Издательство Института Гайдара, 2018. 290 с.

3. Барт Р. Мифологии. / Р. Барт. М.: Издательство М. и С. Сабашниковых, 2004. $234 \mathrm{c}$.

4. Беньямин, В. Произведение искусства в эпоху его технической воспроизводимости / В. Беньямин [Электронный ресурc]. URL: https://forlit.philol.msu.ru/lib-ru/ benjamin1-ru (дата обращения 15.10.21).

5. Бодрийяр, Ж. Симулякры и симуляция / Ж. Бодрийяр. М.: ПОСТУМ, 2018. $320 \mathrm{c}$.

6. Маркс К., Энгельс Ф. Собрание сочинений Т. 1 / К. Маркс, Ф. Энгельс. - М.: Госполитиздат., 1955.698 с.

7. Маркузе, Г. Репрессивная толерантность / Г. Маркузе [Электронный ресурс]. URL: https://avtonom.org/news/gerbert-markuze-repressivnaya-tolerantnost (дата обращения 15.10.21).

8. Спивак, Г. Могут ли угнетенные говорить? / Г. Спивак. [Электронный ресурс]. URL: https://www.wmmsk.com/media/Library/Феминистская\%20теория/Спивак\%20 Г.\%20Могут\%20ли\%20угнетённые\%20говорить.pdf (дата обращения 15.10.21).

9. Терборн, И. От марксизма к постмарксизму? / И. Тереборн. М.: Издательский дом Высшей школы экономики, 2021. $254 \mathrm{c.}$

10. Фуко, М. Надзирать и наказывать / М. Фуко. М.: Ад Маргинем Пресс, 2018. C. 377.

11. Фуко, М. Интеллектуалы и власть: Избранные политические статьи, выступления и интервью / М. Фуко. М.: Праксис, 2002. 384 с.

12. Хоркхаймер, М. Традиционная и критическая теория / М. Хоркхаймер [Электронный pecypc]. URL: https://doxajournal.ru/translations/ctheory (дата обращения 15.10.21). 
13. Foucault, M. Interview: (Polemics, Politics and Problematizations). / Essential Works of Foucault. Vol. 1. Ethics. / Ed. L. Davis. NY, 1997.

14. Mouffe, C. Democratic Politics in the Age of Post-Fordism / Journal Thinking Resisting - Reading the Political. 2008. P. 43-51.

\section{Транслитерация по ГОСТ 7.79-2000 система Б}

1. Adorno, T., KHorkkhajmer, M. Dialektika Prosveshheniya / T. Adorno, M. KHorkkhajmer. [EHlektronnyj resurs]. URL: https://gtmarket.ru/library/basis/5521 (data obrashheniya 15.10.21).

2. Anderson P. Peripetii gegemonii / P. Anderson. - M.: Izdatel'stvo Instituta Gajdara, 2018. $290 \mathrm{~s}$.

3. Bart R. Mifologii. / R. Bart. M.: Izdatel'stvo M. i S. Sabashnikovykh, 2004. 234 s.

4. Ben'yamin, V. Proizvedenie iskusstva v ehpokhu ego tekhnicheskoj vosproizvodimosti / V. Ben'yamin [EHlektronnyj resurs]. URL: https://forlit.philol.msu.ru/lib-ru/benjamin1-ru (data obrashheniya 15.10.21).

5. Bodrijyar, ZH. Simulyakry i simulyatsiya / ZH. Bodrijyar. M.: POSTUM, 2018. $320 \mathrm{~s}$.

6. Marks K., EHngel's F. Sobranie sochinenij T. 1 / K. Marks, F. EHngel's. - M.: Gospolitizdat., 1955. $698 \mathrm{~s}$.

7. Markuze, G. Repressivnaya tolerantnost' / G. Markuze [EHlektronnyj resurs]. URL: https://avtonom.org/news/gerbert-markuze-repressivnaya-tolerantnost (data obrashheniya 15.10 .21$)$.

8. Spivak, G. Mogut li ugnetennye govorit'? / G. Spivak. [EHlektronnyj resurs]. URL: https://www.w mmsk.com/media/Library/Feministskaya\%20teoriya/Spivak\%20G.\%20 Mogut\%20li\%20ugnetyonnye\%20govorit'.pdf (data obrashheniya 15.10.21).

9. Terborn, J. Ot marksizma k postmarksizmu? / J. Tereborn. - Moskva: Izdatel'skij dom Vysshej shkoly ehkonomiki, 2021. $254 \mathrm{~s}$. 377.

10. Fuko, M. Nadzirat' i nakazyvat' / M. Fuko. Moskva: Ad Marginem Press, 2018. S.

11. Fuko, M. Intellektualy i vlast': Izbrannye politicheskie stat'i, vystupleniya i interv'yu / M. Fuko. M.: Praksis, 2002. 384 s.

12. KHorkkhajmer, M. Traditsionnaya i kriticheskaya teoriya / M. KHorkkhajmer [EHlektronnyj resurs]. URL: https://doxajournal.ru/translations/ctheory (data obrashheniya 15.10 .21$)$.

13. Foucault, M. Interview: (Polemics, Politics and Problematizations). / Essential Works of Foucault. Vol. 1. Ethics. / Ed. L. Davis. NY, 1997.

14. Mouffe, C. Democratic Politics in the Age of Post-Fordism / Journal Thinking - Resisting - Reading the Political. 2008. P. 43-51.

\section{Тютченко Д. А. Критическая теория: этапы идейного развития.}

В данной работе дан исторический обзор формирования критической теории, её общих принципов и этапов развития. На примере теории культуры Франкоруртской школы, критической семиотики Ролана Барта, концепции власти Мишеля Фуко, постколониальной теории и постмарксизма рассматривается спектр понятий и подходов, а также методологическая и теоретическая эволюция критической теории.

Ключевые слова: критическая теория, кризис, постколониальная теория, субалтерн, идентичность, марксизм

Tyutchenko D. A. Critical theory: stages of ideological development.

This paper provides a historical overview of the formation of critical theory, its principles and stages of development. Based on the theory of culture of the Frankfurt School, critical semiotics by Roland Barthes, the concept of power by Michel Foucault, postcolonial theory and post-Marxism, an analysis of the spectrum of concepts and approaches, as well as the methodological and theoretical evolution of critical theory.

Key words: critical theory, crisis, postcolonial theory, subaltern, identity, marxism

Для цитирования: Тютченко Д. А. Критическая теория: этапы идейного развития // Ойкумена. Регионоведческие исследования. 2021. № 4. C. 137-145. DOI: 10.24866/19986785/2021-4/137-145

For citation: Tyutchenko D. A. Critical theory: stages of ideological development // Ojkumena.

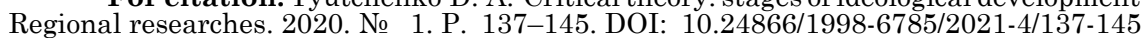

